\title{
SCIENTOMETRIC IMPACT ASSESSMENT OF A RESEARCH POLICY INSTRUMENT: THE CASE OF RATING RESEARCHERS ON SCIENTIFIC OUTPUTS IN SOUTH AFRICA
}

\author{
Roula Inglesi-Lotz ${ }^{1}$ \\ Department of Economics \\ University of Pretoria \\ South Africa \\ Roula.Inglesi@up.ac.za \\ Anastassios Pouris \\ Institute for Technological Innovation \\ University of Pretoria \\ South Africa \\ Anastassios.Pouris@up.ac.za
}

\footnotetext{
${ }^{1}$ Corresponding Author

Department of Economics, University of Pretoria, 0002 Pretoria

Email: roula.inglesi@up.ac.za

Work tel: (0027) 0124204504
} 


\begin{abstract}
The influence of the National Research Foundation's (NRF) rating system on the productivity of the South African social science researchers is investigated scientometrically for the period from 1981 to 2006 . Their output performance is mainly indicated by their research publications.

Following international best practice in scientometrics as well as the behavioural reinforcement theory, we employed the "before/after control impact (BACI) method", as well as the well known econometric breakpoint test as proposed by Chow. We use as control group the publications in the field of clinical medicine. The field is not supported by NRF and hence clinical medicine researchers are not affected by the evaluation and rating system.

The findings show a positive impact of the NRF programme on the research outputs of social sciences researchers and the implementation of the programme has increased the relevant population of research articles by an average of $24.5 \%$ (during the first five years) over the expected number of publication without the programme. The results confirm the scientometric findings of other studies (e.g. that of Nederhof) that ratings promulgate research productivity.
\end{abstract}

Keywords: Scientometrics; incentives; research policy; quasi experimental design; South Africa 


\section{Introduction}

During the last two decades, there has been substantial growth in higher education quality assurance systems throughout the world and particularly in research evaluation. Evaluation or assessment has emerged as a key issue in many countries where universities are faced with demands for greater accountability and governments require value for money for public expenditure on higher education. At the end of the 1990s there were more than 50 agencies worldwide that played a role related to quality assessment or quality assurance. In a number of cases these agencies have been mandated by governments and followed a design developed by government officials. In other cases the systems have been developed by semiindependent government agencies and were sustained by the support and goodwill of the research communities they serve.

The South African government established a research funding agency, the National Research Foundation (NRF) during the 1980s (originally named the Foundation for Research Development (FRD)). The agency introduces various programmes for funding academic research. However, the main innovation novelty initiated by FRD (now NRF), is the evaluation and rating for individuals system.

At the time of its initiation, the rating approach of researchers in higher education was based solely on previous performance and outputs in research and the funding decision for rated researchers was not based on the evaluation of submitted proposals.

In 2001, the direct linkage between rating and funding support was discontinued. The NRF justified the decision to do so due to lack of available funding. However, in 2007, the NRF announced a partial link of researcher evaluation and rating with financial support.

Social sciences researchers were introduced in the NRF evaluation and rating system only in 2001 while natural sciences and engineering researchers have been part of the system since its inception. The introduction of social sciences researchers into the NRF system presents a unique opportunity to investigate the issue of the effect of NRF programmes to the research performance in social sciences.

The objective of this investigation is to examine the hypothesis that the NRF evaluation and rating system for individuals had a positive impact on the 
publication profile of the country's social sciences researchers. The paper is structured as follows: the next section discusses the history of the NRF as well as its major policy intervention i.e. the evaluation and rating system of individuals;; the methodology and data used are presented in the subsequent section; the empirical results of the study are reported next; and in the final section 6 discusses the results of the investigation.

\section{Background: National Research Foundation (NRF)}

In 1942, General Jan Smuts was the first to express a vision for a national research body in South Africa, as support for research in universities. The Council for Scientific and Industrial Research (CSIR) was established in 1945 with the main goal to foster research in universities through grants and bursaries. In 1952, specialised university committees assessed applications and allocated funds accordingly.

In the 1980s, South African research scientists at universities and museums complained that the research support funding was not allocated equally. Prof Jack de Wet was asked to give advice to the Council for Scientific and Industrial Research (CSIR) on future options for research funding.

In 1984, after De Wet's suggestions, the CSIR Foundation for Research Development (FRD) was established and in 1990, it became independent from the CSIR. FRD's main purpose was to invest its funding in researchers with a track record of quality research outcomes - that funding was linked to researchers' rating. The main novelty of the FRD was that it established the quality of the researcher's outcomes as well as their student's outcomes as the main criterion for research rating and hence funding (Pouris, 2007).

In April 1999, the National Research Foundation (NRF) - a new government funding agency - was established as an amalgamation of the FRD and the Centre of Scientific Development (CSD) of the Human Sciences Research Council (HSRC). The objective of the NRF is the support and promotion of research through various programmes encouraging the human resource development and the provision of research facilities, with higher purpose to assist the innovation and development in fields of natural and social sciences, humanities and technology. 
The NRF provides funding for research support and postgraduate research training; NRF's vision is to be a key institution to the country's goal on creating an innovative, knowledge-driven society (NRF, n.d.). Promoting research capacity development is another key area of NRF's expertise in order to take the research community into its full potential and establish equity.

\section{Evaluation and Rating of Individuals in South Africa}

During the NRF's foundation in 1999 (by the time the FRD and the Centre for Science Development of the HSRC merged), the linkage between rating and funding became well established. The rating of individual researchers in higher education at the time was based on their recent track records and outputs in research and their funding of rated researchers was not dependent on proposal assessment. Their level of financial support was linked to their rating. The A-rated researchers, for instance, were receiving substantially larger grants than the Brated researchers.

The rated researchers are classified into five broad categories: A, B, C, Y and P. A-rated scientists are those who are recognised by their peers as top international scholars in their field for the quality and impact of their research. Researchers that are B-rated, enjoy considerable international recognition by their peers. C-rank is achieved by established researchers with a sustained record of productivity recently. $\mathrm{P}$ and $\mathrm{Y}$ rated researchers are young scholars that have shown potential for future international careers.

The process for evaluation and rating of individuals is as follows: Applications for evaluation and rating are invited annually by NRF. The application is screened and approved by the applicant's institutional research administration, which in turn submits it electronically to the Monitoring and Evaluation (M\&E) unit of the NRF. The unit screens the application for acceptance and acknowledges receipt of the documents. The documentation is then sent to members of subject-specific Specialist Committees that recommend at least six suitable peer reviewers. The M\&E unit sends the relevant documentation to the peer reviewers who provide an appraisal/evaluation on the following two criteria:

- The quality of the research-based outputs of the last seven years as well as the impact of the applicant's work in his/her field and how it has impacted on adjacent fields. 
- An estimation of the applicant's standing as a researcher in the field in terms of both a South African and international perspective.

The set of reviewers' reports is sent to members of the Assessment Panels (Specialist Committees plus an independent assessor) by the M\&E unit. The Panels assess the standing of applicants amongst their peers and recommend a rating for them on the basis of the statements contained in the reviewers' reports and on the objectivity of these reports in the light of the factual information contained in the submission documentation.

More specifically, the members of the Specialist Committee meet in order to rate the applicants. When the Specialist Committees have reached consensus about the ratings of the applicants they are joined by the Chairperson and the Assessor and the formal meeting of the Assessment Panel commences. Each applicant is discussed in turn. The Convenor of the Specialist Committee presents the rating recommended by the Specialist Committee, the Assessor puts forward his/her independent suggested rating and the Chairperson facilitates a decision in each case, often also playing the role of a second independent assessor. Rating of individuals is awarded for five years after which time the researchers are invited to resubmit applications for re-evaluation.

A benefit of the new system was the fact that it reduced bureaucracy for both applicants and reviewers, who did not have to submit and review proposals and instead, relied on the trust that past performance is a good predictor of future activities.

In 2001, the direct linkage between rating and funding support was decided to be discontinued. The reasons offered were the lack of funding to firstly support the developmental programmes within the Foundation and secondly to support the social sciences and humanities researchers who had become the responsibility of NRF during that year (social sciences researchers were introduced in the NRF system only in 2001).

However, the rating system provided rated researchers with certain advantages in various programmes such as:

- $\quad$ Five-year grants were given only to rated researchers (unrated researchers could only qualify for two-year grants) on the basis of successful research proposals; 
- Unrated researchers qualified for a maximum of six years funding (three two-year grants) and after this period, they would have to be rated to qualify for funding;

- $\quad$ Rated researchers who allowed their ratings to lapse or lost their rating were not eligible for funding until they regained their rating.

In 2007, after a number of assessments, the NRF announced the linking of researcher evaluation and rating with financial support. A-rated researchers would receive research funding of R100 000, ${ }^{2}$ B-rated researchers R80 000 and C-rated researchers R40 000 per year and so on, during the period that they maintain their ratings. This was solely based on the rating and was aimed in supporting any research activities that these researchers were undertaken.

The results of the rating of individual researchers are disseminated within the higher education system and the country's universities encourage their researchers to apply for rating. Research-intensive universities in the country use the rating system for competition and marketing purposes and they announce regularly the number of the rated scientists employed by their institution.

Furthermore, numerous universities have incorporated the rating system in their promotion and remuneration policies as an extra incentive for their researchers. For instance, the University of Pretoria increases the salary of the A-rated researchers by R100 000 for the period that they maintain that rating and only Brated researchers, or better, qualify for annual performance awards. The behavioural reinforcement theory (Skinner 1969) suggests that the impact that such a system is expected to have is an increase of the quantity and quality of research publications from the country's researchers. Researchers are aware of the fact that in order to be assessed by the NRF and promoted by their institutions need to have a considerable number of publications in internationally refereed journals. Their own ambitions and the pressure from their administrations direct them to improve their publication profile by producing more publications and redirecting their articles to international journals, aiming to improve their international exposure.

It should be emphasized that in South Africa, the culture of publishing is not prevalent across all universities and research institutions. The majority of South African universities produce a limited number of publications and even the 
country's research-intensive institutions produce less than one publication per member of staff annually. Habib and Morrow (2007) have attributed this fact to four barriers to research productivity:

- Insufficient academic remuneration and inadequate working conditions;

- $\quad$ Tension emerging between advancing equity and realising academic excellence;

- $\quad$ Barriers to institutional collaboration with the universities and science councils;

- $\quad$ Poor management performance in the knowledge system.

Hence, it should be expected that the NRF system will have an impact in researcher outputs until the researchers' productivity reaches its limit or the researchers are not well-motivated by the offerings (promotion, research resources, etc.) of the system, e.g. due to alternative offerings.

The NRF rating system has been the subject of discussion and debate since its inception. In some NRF funding programmes rated researchers qualify for longer duration funding and research proposals by rated researchers were, for a period, not sent to postal peer review but were discussed directly by the relevant review panels.

It has often been argued that the NRF rating system is "novel" and hence it does not comply with international standards. However, a number of countries (i.e. Mexico (Arenas et al. 2000), New Zealand (TEC 2006), and Taiwan (Tien et al. 2007) use similar approaches as policy instruments aiming to promote and support excellent research or in order to minimize the relevant social costs. Furthermore, the quality of the research of the applicant is an important factor in all funding decisions. In Australia, the National Competitive Grants Programme allocates $50 \%$ of weight for funding proposals on the quality of the applicant's research. In the South African context the rating system has the potential to become a powerful policy instrument by linking appropriate financial support to it (as it is currently happening). The instrument will have the potential to provide incentives to excellent researchers to remain in the country or foreign researchers to move in the country. In addition, the instrument will provide incentives to researchers to aim towards excellence and will contribute towards making the academic profession a desirable objective for students. Furthermore, such an approach has the potential to reduce the social costs of funding research in the country by not 
requiring researchers to write proposals (or requiring short proposals) in order to receive funding.

\section{Impact assessment studies}

The term "impact assessment" refers to the identification of changes in the outcomes of individuals because of the existence of a particular programme. For instance, the evaluation of a government programme involves comparing outcomes associated with the participation - or broadly, the existence of the programme - and non-participation (or non-existence of) in the programme. Impact assessment is different from efforts focusing in reporting outcomes for participants in an activity (e.g. surveying the performance of participants in a clinical survey after the treatment); it is distinctly different from "process evaluation" that seeks to assess the operation of a particular programme (i.e. identifying if the function is performed as it was planned and if it is performed in an efficient way) and it is a narrower effort than cost benefit assessments. Particularly in the fields of health (Morgan 2008), environment (Caspary 2009), and agriculture (Raitzer and Kelly 2008), impact assessment is a widespread activity. Relatively, fewer impact assessments are published related to research and development (R\&D) initiatives probably due to the challenges associated with the field and the lack of researchers with expertise in impact assessment and science and technology policy.

There are number of different approaches used for the impact assessment studies internationally (Tassey 2003). The most often used are experimental and quasi experimental designs for causal assessment (Shadish et al 2003; Duflo et al 2006; and Smith et al. 1993). Socio-economic future scenarios and indicators can also be used as qualitative assessments of the impact of various policy changes by providing quantitative inputs for model-based assessment studies (Berkhout et al. 2002). In addition, quantitative analysis is not the only approach employed for impact assessment. Momtaz (2002) conducted interviews with relevant employees in Bangladesh in order to assess environmental impact after the initiation of such guidelines in 1992.

During the last decade, a number of studies have used such approaches for a variety of assessments ranging from identifying the impact of policies on 
corruption in driving licences administration (Bertrand et al 2006), to estimating the effects of minimum wages on unemployment (Leigh 2003) and to evaluating different policy measures on education (Kremer 2003).

In the field of science policy, Kim (2007) estimated the effectiveness of Korea's biotechnology stimulation plans on the number of publications and Nederhof (1988) investigated the effects of government stimulation programmes on publications in six industrial nations.

\section{Methodology and Data}

\section{Methodology}

Investigating and quantifying the impact of research on other research, on technology, on company performance, profitability and similar has a long tradition (Johnston 1995). Investigating the impact of socio-economic conditions, research programs and similar on the research outputs is a less often phenomenon in the open literature.

Among the latter investigations recent examples include the following:

Bouabid et al (2010) investigated using scientometric indicators (publications and patents) the impact of the voluntary early retirement policy on research and technological outputs of the faculties of science in Morocco and consequently on the overall Morocco's research system. Similarly Miguel et al (2010) investigated the impact of the socioeconomic crisis of 2001 on the scientific system of Argentina from a scientometric perspective.

Nederhof (2008) investigated the effects of a yearly public ranking of individual researchers and their institutes in economics by means of their publication output in international top journals. The ranking of economic researchers in the Netherlands on quantity and quality of research output was initiated in order to induce improvements in research output in international journals and raising standards of research performance on a national level. The author suggests that as a result "Dutch economists felt they were engaged in a ranking competition, and in particular the most prolific tended to participate both eagerly and combatively". As control groups with the strict meaning of the word they were not available the author suggested that "performance results of the Dutch economists can be compared with those of researchers in the Netherlands in other fields, and with those of economists in other countries lacking the ranking scheme." 
Older studies include Jain et al (1998) who investigated the impact of SERC's funding on research in chemical studies in India, Nederhof ' $\mathrm{s}(1988)$ investigation of the changes in publication patterns of biotechnologists in lieu to government stimulation programs and others.

In this article we report the results of an evaluation National Research Foundation's (NRF) rating of individuals system on the productivity of the South African social science researchers using the same scientometric approaches used by Nederhof (2008), Miguel (2010) and others.

The quasi experimental design of "before/after control impact (BACI) method" is used. The BACI method estimates impact by comparing outcomes for the treated discipline after the treatment with outcomes for the same group or matched control group in the period prior to participation. If the treatment is an existing activity, it may be impossible to calculate the before conditions. In such cases, studies might make use of an unaffected or control sample and used those data for comparisons.

The main idea of this method is to match policy-treated groups (disciplines) with "untreated" groups (disciplines) that are not affected by the treatment (i.e. country's science policies).

One of the concerns related to BACI approach is the fact that the technique does not account for possible confounding factors, apart from the intervention, that may have created the identified impact. In order to resolve this issue, the method uses the matching groups approach, whose main advantage compared to BACI is that it can control for the influence on the outcome variable of unobservable factors that vary across time and in this specific analysis for factors that may affect the whole research system.

The time series of the number of research publications in social sciences is to be examined for structural breaks after 1999. At this point, it is very useful to define what a structural break is. This is a concept used mostly in economics and is considered to appear when an unpredicted shift occurs at a specific point in a time series. It is usually the result of a factor, other than the typical factors that affect the specific variable, such as political changes in the country, policy implementations, weather conditions etc.

The proposed test applied in this study is the Chow test. This test was developed by economist Gregory Chow (Chow 1960) and is most commonly used in time 
series analysis to test for the presence of structural breaks. The mechanics of the Chow test are relatively simple: estimate the residual sum of squares of the initial regression, which is called the restricted residual sum of squares; then, divide the period sample in two smaller ones (the first one ends at the year where a structural break is expected to be and the second one starts from the period after the structural break); calculate the residual sum of squares for each sample; add the two residual sums of squares, the sum is called the unrestricted sum of squares; there is in fact a structural break if the restricted and unrestricted sum of squares are statistically different (Gujarati 2003).

\section{Data}

The source of data for the bibliometric analysis is the National Science Indicators database of the Institute for Scientific Information (ISI). ISI currently indexes more than 6000 of the world's leading scholarly scientific and technical journals, approximately 1800 social sciences journals, and 1150 titles from the arts and humanities journals. All journals indexed by ISI are peer reviewed.

In South Africa, the Department of Education recognizes the ISI journals for higher education subsidy purposes and the NRF, in evaluating scientists for financial support, is influenced by their citation profile. The latter can be compiled only if the researcher publishes in ISI indexed journals.

In the National Science Indicators database the ISI counts articles, notes, reviews and proceeding papers, but not other types of items and journal marginalia such as editorials, letters, corrections, and abstracts.

One of the major advantages of using the ISI databases for policy analysis is the fact that ISI indexes all authors' addresses, not just the first or reprint address for each paper and hence a comprehensive coverage can be achieved.Finally, individual articles are divided into fields on the basis of the journal in which the articles appeared. For this investigation we utilize the articles indexed under the disciplines "social sciences" and "clinical medicine". A number of sub-disciplines were considered for further examination. We excluded those sub-disciplines from the investigation because of the small size of publications per year. (Table 1). The decision that the sample size to be examined will end in 2006 was based on the finding that after 2006 ISI has changed substantially the number of journals indexed. From 2006 onwards, ISI has included additional journals published in 
South Africa. Therefore, the comparison with the year post 2006 would be unfair and would not produce reliable results.

To address the possibility of international aspects affecting the South African social scientists' publication performance, we estimate the percentage of South African papers in the field as a share to the world's social sciences publications, in Figure 1. If the share remains constant after the year 2001, we may conclude that there were particular international conditions affecting both the worldwide and South African publications. As presented in Figure 1, the South African share increased showing that there was a local effect.

With the intention to make sure that the data reflect the institutions influenced by NRF, we identified the producers of social sciences research in South Africa. The institutions that produce the majority of social sciences publications are mainly the universities (89.3\% of all the publications for the period 1994-2006), as shown in Table 2. When we take into account museums, national facilities and hospitals which may also affected by NRF policies, the number of affected publications is much higher.

\section{Empirical results}

The Chow test is considered to be an F-test, where the null hypothesis to be tested is "No structural break". The results reported in Table 3 show a breakpoint in the year 2001. At a 1\% level of significance, the F-statistic (47.372) with probability 0.000 indicates a rejection of the null hypothesis; hence, we can conclude that a structural break did occur in 2001.

This finding is within our expectations. The incorporation of the social sciences into the NRF system was finalized with the publication of the NRF Act of 1998. As it became public knowledge that NRF was to become responsible for the support of social sciences, relevant researchers, on the expectation that the NRF programmes affecting other disciplines will affect them as well, started publishing in international journals and increased their productivity. Within two years, the additional publications were published in the international literature (2001) and the discontinuity became detectable. It should be mentioned that the identified discontinuity was not the effect of an annual "blip" but it persisted and created a new trend in the data. 
Figure 2 shows the actual data for the period 1981 to 2005 and the projected data for the period 2001-2005. The projected data have been estimated through regression of the social sciences data for the period 1981-2000. The area between the projected data line and the actual data line is indicative of the impact of the policy change.

The mean of the projected values for the period 2001-2005 is 166.8 and the mean of the differences actual to projected data is 41.2. Hence the estimated impact over the projected values for the 5 year period is $24.7 \%$.

We use as control group the publications in the field of clinical medicine. The field is not supported by NRF and hence clinical medicine researchers are not affected by the evaluation and rating system.

We undertake a two sample t-test in order to determine if the two population means are equal. We expect to find out that before treatment the two populations were behaving similarly and that after the treatment that the two population means are different.

Table 4 shows the mean growth rates of publications in social sciences and clinical medicine for the period (1995-2000) before the discontinuity in 2001. We test the null $\left(\mathrm{H}_{0}\right)$ hypothesis that the two means are equal: $\mu 1=\mu 2$ with alternative hypothesis that the two means are not equal: $\mu 1 \neq \mu 2$ The t-stat (0.29) is smaller than the critical value of the $t$ distribution (1.94) with 6 degrees of freedom at $5 \%$ level of significance. Hence, we have to accept the null hypothesis that the two means are equal and that clinical medicine publications can be used as a control group.

Table 5 shows the mean growth rates of publications in social sciences and clinical medicine for the period (2001-2006) after the discontinuity in 2001. The $t-$ stat (2.4) is bigger than the critical value of the $t$ distribution (1.8) with 10 degrees of freedom at $5 \%$ level of significance. Hence, we have to reject the null hypothesis that the two means are equal.

The difference in the means of growth rates is indicative of the impact of the rating system on the social sciences publications. During the post treatment period social sciences publications grew by $15.3 \%$ per year while clinical medicine publications grew by $2.5 \%$ per annum.

The results demonstrate that the NRF researcher evaluation program has caused a significant increase in quantity of research. We have further investigated the issue 
of the quality of research by investigating the relative impact of South African social sciences papers to field. The relative impact to field is estimated as the citation impact of a country's articles in a particular field divided by the citation impact for the field as a whole worldwide.

$$
\text { Relative impact }=\left(\mathrm{c}_{\mathrm{i}} / \mathrm{p}_{\mathrm{i}}\right) /\left(\mathrm{c}_{\mathrm{w}} / \mathrm{p}_{\mathrm{w}}\right)
$$

Where $\mathrm{c}=$ total citations received, $\mathrm{p}=$ total papers for country-field combination I and field as a whole w.

Figure 3 illustrates the fact that the relative impact increased significant to 1.2 in 2002 and then showed a downward trend, returning to its mean $(0.8)$ for the period 1981 to 2000. The relative impact information is provided in the National Sciences Indicators database of ISI Thomson Reuters.

\section{Discussion}

This article reports an effort to identify the impact of NRF's evaluation and rating system on the social sciences publications in South Africa. We use scientometric information and a quasi experimental design in order to test the hypothesis that NRF has a positive impact on the research outputs of researchers belonging to the domains supported by the organization. We argue that the NRF system, supported by the universities' administrations in the country, provides continuous incentives for researchers to become prolific and to publish in international, ISI indexed, journals. The inclusion of social sciences in the disciplines supported by NRF provides a unique opportunity to test our hypothesis using a quasi experimental design.

The application of experimental and quasi experimental methods to policy evaluation is at a very early stage in South Africa. Experimental and quasi experimental methods are a new powerful set of tools for empirical analysis and evaluation of government and agency policies. They are used extensively in countries such as the United States, Canada, the United Kingdom and other European countries, and within international agencies such as the World Bank. Our hypothesis is supported theoretically by the behavioural reinforcement theory. According to the theory, human behaviour is determined to a certain extent by environmental factors. The NRF rating system in conjunction with the 
universities' policies to link the rating of academics to faculty promotions is expected to have a motivating effect on productivity.

Our analysis indicates that the NRF has a positive impact on the research outputs of social sciences researchers and that the implementation of the programme has increased the relevant population of research articles by an average of $24.5 \%$ (during the first five years after the implementation of the programme) over the expected number of publications without the programme. This finding is in accordance to theory and with the findings in other disciplines (Pouris 1991) and other countries (Nederhof 2008; Groot and Garcia-Valderrama 2006). Evaluation and rating of researchers affects their behaviour and improves their productivity. Hence, research and policy administrations can use the approach in order to improve their research domains.

It is tempting to argue that the estimated impact applies across the board for all scientific disciplines supported by NRF (external validity). However, the average causal effect that we estimated is not necessarily representative of the average causal effect for the entire population of all scientific disciplines. Depending on circumstances, it may or may not be representative of another sub-population of interest (e.g. clinical medicine). For example, clinical medicine researchers may already publish the majority of their research abroad and hence, they would not have the opportunity to switch their publications from local to international journals as researchers in other disciplines can do. In other words, another impact will appear in treating a different sub-population although it will not bias the estimation of the causal effect for social sciences researchers.

Spill-over effects may have affected our estimates. For example, social sciences researchers may have started producing more publications in international refereed journals well before NRF took over the responsibility to support social sciences. Such a spill-over may have been created on the basis of predictions that at some future point NRF will also support social sciences or on the basis of learning and imitation. Such a spill-over will mean that the actual rating system impact is higher than the estimated one.

In this investigation the question of interest is the effect of the intervention (programme) on the publication output in general rather than on the effect of each subject (researcher) separately. Measurement of such overall effects has its roots in the literature on clinical trials and on meta-analysis. However, there are a 
number of issues that cannot be answered through this approach and they require some form of randomization at the level of individuals. Such further investigations could identify whether the effect of the programme is different from prolific to tail end researchers; whether the effect varies depending on the complementary incentive approaches followed by the various universities and others.

\section{Acknowledgements}

The authors wish to thank Mrs A Pouris, Grants Director, NRF and two anonymous referees for their constructive comments of an earlier version of the article. The normal caveat applies.

\section{References}

Arenas, J.L.D., Valles, J., Arenas, M. (2000).Educational research in Mexico: socio-demographic and visibility issues, Educational Research. 42, 85-90.

Berkhout, F. Hertin, J. Jordan, A. (2002). Socio-economic futures in climate change impact assessment: using scenarios as "learning machines", Global Environmental Change 12, 83-95.

Bertrand, M. , Djankov, S., Hanna, R. Mullainathan, S. (2006) Does Corruption Produce Unsafe Drivers? National Bureau of Economic Research NBER Working Paper \#12274 Cambridge, MA 02138.

Bouabid H, Dalimi M, Elmajid Z (2010) Impact Evaluation Of The voluntary early retirement policy on research and technology outputs of the faculties of science in Morocco, Scientometrics, doi: 10.1007/s11192-010-0271-z.

Caspary, G. (2009) Assessing, mitigating and monitoring environmental risks of large infrastructure projects in foreign financing decisions: the case of OECD country public financing for large dams in developing countries. Impact Assessment and Project Appraisal, 27, 19-32.

Chow, C.G. (1960) Tests of Equality between sets of coefficients in two linear regressions. Econometrica 28, 591-605.

Duflo, E. Glennerster, R. Kremer, M. (2006) Using Randomization in Development Economics Research: A Toolkit, National Bureau of 
Economic Research (NBER), Technical Working Paper 333, Cambridge, MA 02138.

Groot, T., Garcia-Valderrama, T. (2006) Research quality and efficiency - An analysis of assessments and management issues in Dutch economics and business research programmes, Research Policy 35, 1362-1376.

Gujarati, D.N. (2003) Basic Econometrics. New York: McGraw-Hill Companies Inc.,.

Habib, A., Morrow, S., (2007). Research, Research Productivity and the State in South Africa.Journal of Higher Education in Africa. 5, 113-130.

Jain A, Garg Kc, Sharma P, Kumar S (1998) Impact Of Serc's Funding on research in chemical sciences, Scientometrics 41, 357-370

Johnston R (1995) Research Impact Quantification, Scientometrics 34 (3) 415-426

Kim, M.J. (2007) A bibliometric analysis of the effectiveness of Korea's biotechnology stimulation plans with a comparison with four other Asian nations, Scientometrics 72, 371-388.

Kremer, M. (2003). Randomized Evaluations of Educational Programmes in Developing Countries: Some Lessons. American Economic.Review 93,102106.

Leigh, A. (2003) Employment effects of minimum wages: Evidence from a quasiexperiment, Australian Economic Review 36, 361-373.

Miguel S, Moya-Anegon F, Herrero-Solana V (2010), The Impact of the socioeconomic crisis of 2001 on the scientific system of Argentina from the scientometric perspective, Scientometrics $85,495-507$

Momtaz, S. (2002) Environmental impact assessment in Bangladesh: A critical review. Environmental Impact Assessment Review 22, 163-179.

Morgan, R.K. (2008) Institutionalising Health Impact assessment: the New Zealand experience. Impact Assessment and Project Appraisal, 26, 2-6.

National Research Foundation. [online] NRF profile, Not dated (n.d) Available from $<$ http://www.nrf.ac.za/profile/\#mission>. 
Nederhof A. J. (2008) Policy Impact of Bibliometric Rankings of Research performance of departments and individuals in economics, Scientometrics $74,163-174$

Nederhof, A.J. (1988) Changes in Publication Patterns of Biotechnologists: an Evaluation of the Impact of Government Stimulation Programmes in Six Industrial Nations, Scientometrics 15, 475-484.

Pouris, A. (1991) Effects of Funding Policies on Research Publications in South Africa. South African Journal of Science 87, 78-81.

Pouris, A., (2007). The National Research Foundation Rating System: Why Scientists let their ratings lapse. South African Journal of Science, 103, 439442.

Raitzer, D. A., Kelley, T.G. (2008) Assessing the contribution of impact assessment to donor decisions for international agricultural research, Research Evaluation, 17, 187-199.

Shadish, R. W., Cook, D.T. Campbell, T.D. (2003) Experimental and Quasi Experimental Designs for Generalised Causal Inference, Houghton Mifflin Company, Boston and New York.

Skinner, B.F., (1969). Contingencies of Reinforcement: A theoretical analysis. New York: Englewood Cliffs, NJ: Prentice Hall.

Smith, P.E. Orvos, R.D. Cairns Jr, J. (1993) Impact Assessment Using the BeforeAfter-Control-Impact (BACI) Model: Concerns and Comments, Canadian Journal of Fisheries and Aquatic Sciences 50, 627-637.

Tassey, G. (2003). Methods for Assessing the Economic Impacts of Government R\&D. National Institute of Standards and Technology, [Online] Available at http://www.nist.gov/public_affairs/budget.htm.

Tien, F.F. (2007) Faculty Research behaviour and career incentives: the case of Taiwan. International Journal of Educational Development. 27, 1-7. 
Table 1 Sub-disciplines included in Social Sciences field

Source: National Science Indicators Database: ISI

Table 2 Top 20 Institutions in publications in the Social Sciences field (1994-2006)

Source: ISI Web of Knowledge

\begin{tabular}{ll}
\hline Main field & Sub-disciplines \\
\hline Social Sciences & Communication \\
& Environmental studies, Geography \& Development \\
& Library \& Information Sciences \\
& Political Sciences \& Public Administration \\
& Public Health \& Health Care Studies \\
& Rehabilitation \\
& Social Work \& Social Policy \\
& Sociology \& Anthropology
\end{tabular}

\begin{tabular}{llll}
\hline & Institution name & $\begin{array}{l}\text { Record } \\
\text { count }\end{array}$ & $\begin{array}{l}\text { \% of total } \\
(1339)(\%)\end{array}$ \\
\hline 1 & University of Cape Town & 291 & 21.73 \\
2 & University of Witwatersrand & 209 & 15.61 \\
3 & University of Pretoria & 140 & 10.46 \\
4 & University of Stellenbosch & 121 & 9.04 \\
5 & University of Natal & 118 & 8.81 \\
6 & Rhodes University & 66 & 4.93 \\
7 & University of Durban Westville & 40 & 2.99 \\
8 & CSIR & 36 & 2.69 \\
9 & University of Port Elizabeth & 35 & 2.61 \\
10 & University of Western Cape & 34 & 2.54 \\
11 & Rand Afrikaans University & 24 & 1.79 \\
12 & Potchefstroom University & 23 & 1.72 \\
13 & University Orange Free State & 21 & 1.57 \\
14 & University of Zimbabwe & 17 & 1.27 \\
15 & University of Kwazulu Natal & 16 & 1.19 \\
16 & University of Zululand & 16 & 1.19 \\
17 & MRC & 15 & 1.12 \\
18 & University of Sussex & 14 & 1.05 \\
19 & National Botanical Gardens & 12 & 0.90 \\
20 & University of South Africa & 11 & 0.82 \\
\hline & & &
\end{tabular}


Table 3 Result of Chow breakpoint test

\begin{tabular}{llll}
\hline$F$-statistic & 47.3724 & Probability & 0.0000 \\
Log likelihood ratio & 28.3363 & Probability & 0.0000 \\
\hline
\end{tabular}

Table 4 Univariate test: annual publication growth rate in social sciences and clinical medicine (control) before treatment (1995-2000)

\begin{tabular}{lcll}
\hline & $\begin{array}{l}\text { Social sciences } \\
\text { publication } \\
\text { growth }\end{array}$ & $\begin{array}{l}\text { Control: clinical } \\
\text { medicine } \\
\text { publication } \\
\text { growth }\end{array}$ & T-stat \\
\hline $\begin{array}{c}\text { Mean: growth rate; } \\
\text { before treatment }\end{array}$ & 2.39 & 0.54 & 0.29 \\
$\begin{array}{c}\text { Variance: growth rate; } \\
\text { before treatment }\end{array}$ & 212.4 & 24.9 & \\
\hline
\end{tabular}

Table 5 Univariate test: annual publication growth rate in social sciences and clinical medicine (control) after treatment (2001-2006)

\begin{tabular}{llll}
\hline & $\begin{array}{l}\text { Social sciences } \\
\text { publication growth }\end{array}$ & $\begin{array}{l}\text { Control: clinical } \\
\text { medicine publication } \\
\text { growth }\end{array}$ & $T$-stat \\
\hline Mean: growth rate; after treatment & 15.3 & 2.5 & 2.4 \\
Variance: growth rate; after treatment & 65.2 & 99.2 & \\
\hline
\end{tabular}




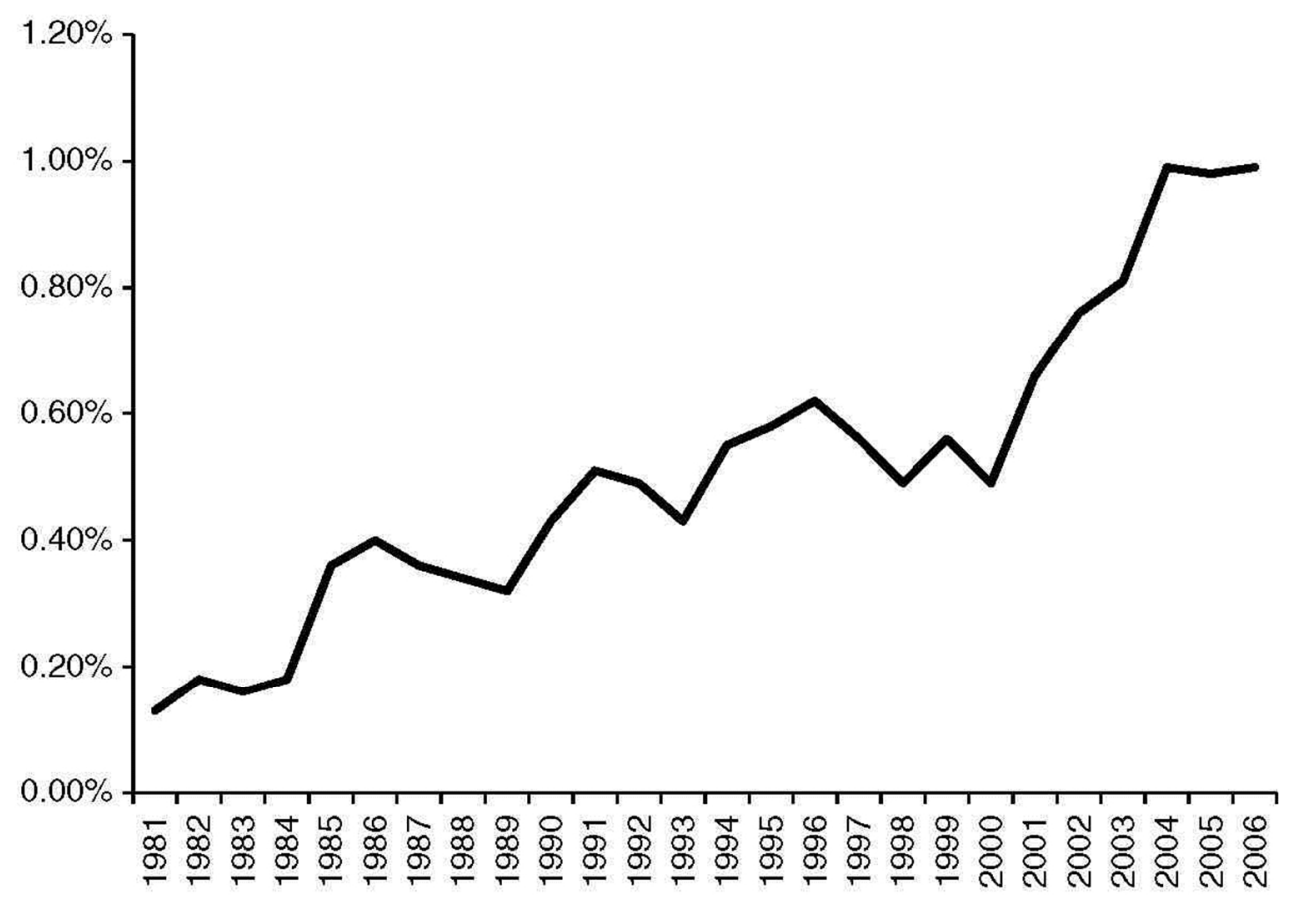

Fig. 1 South African social sciences publications as a percentage to world social sciences publications (1981-2005). Source: National Science Indicators Database: ISI

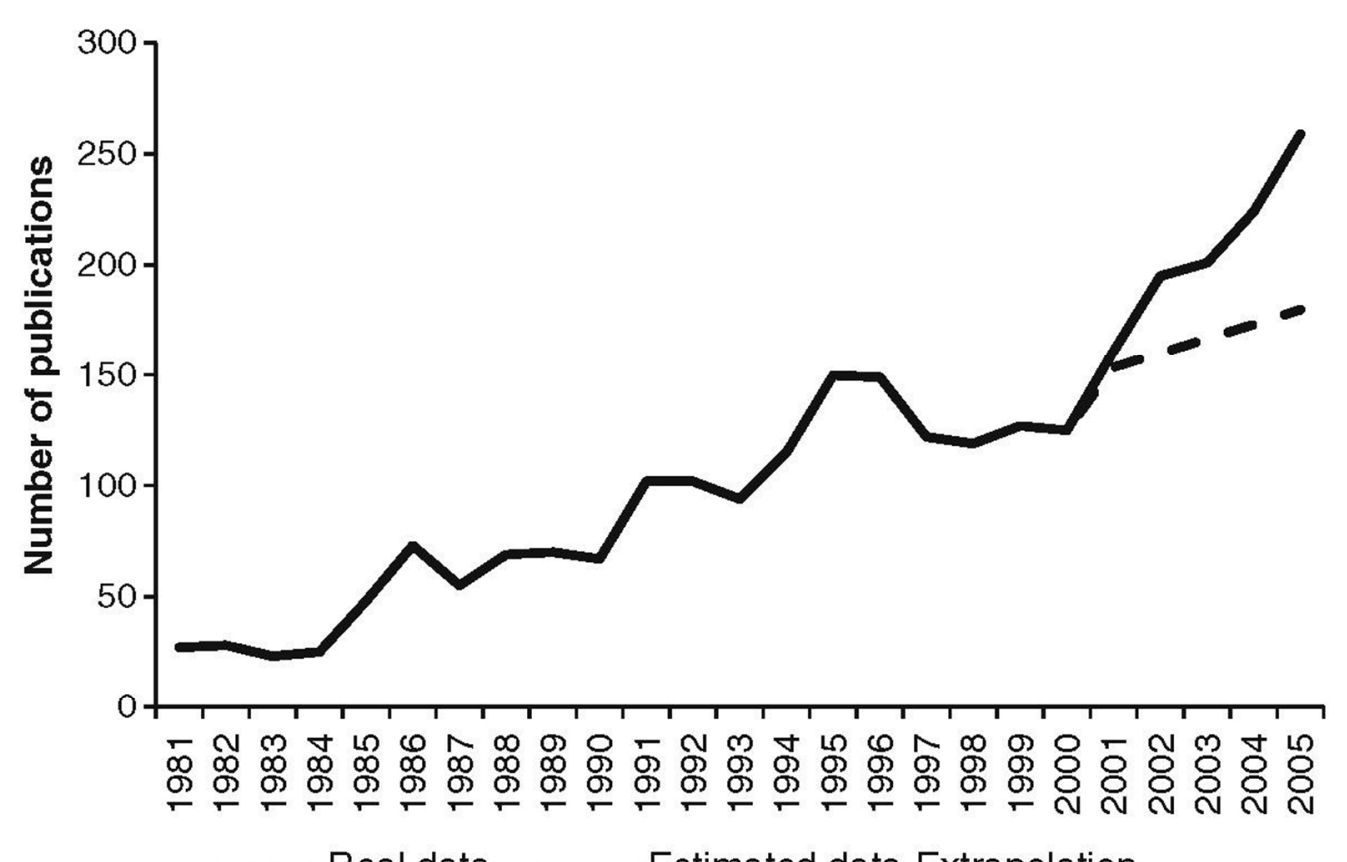

Fig. 2 South African publications in social sciences (1981-2005). Source: National Science Indicators Database: ISI and authors' calculation 


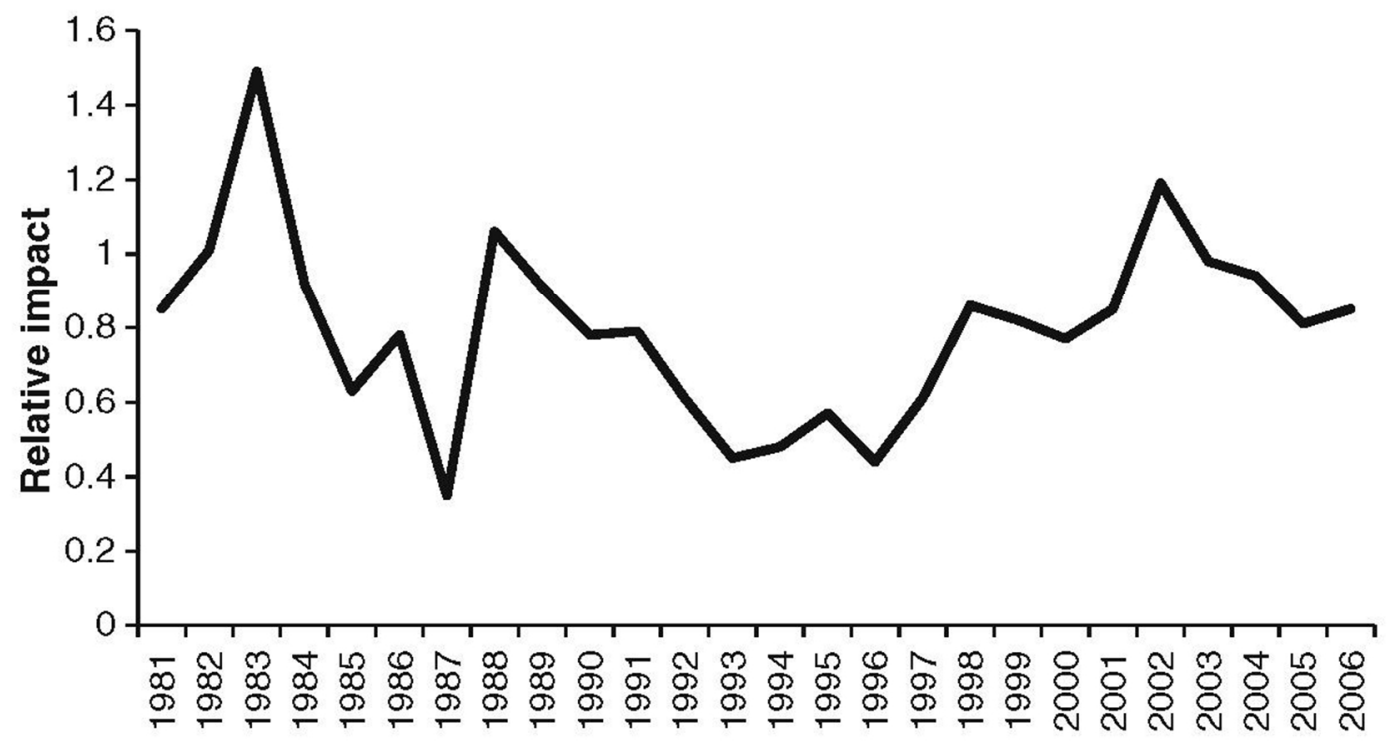

Fig. 3 Impact of South African social sciences papers to field (1981-2006). Source: National Science Indicators Database: ISI 